\title{
Suíte acadêmica: apontamentos poéticos para elaboração de projetos de pesquisa em Comunicação
}

\author{
Academic suite: poetic notes for the \\ elaboration of research projects in \\ Communication
}

\author{
- Jo Ão a nZanello CarrascozA* \\ Universidade de São Paulo, Escola de Comunicações e Artes, Departamento de Relações Públicas, \\ Propaganda e Turismo da ECA-USP. São Paulo - SP, Brasil \\ Escola Superior de Propaganda e Marketing, Programa de Pós-Graduação em Comunicação e Práti- \\ cas de Consumo. São Paulo - SP, Brasil
}

\section{RESUMO}

Metodologia de Pesquisa é disciplina obrigatória nos cursos de pós-graduação stricto sensu no campo da Comunicação. Obras sobre o assunto, embora de qualidade, limitam-se a discutir a elaboração de projetos de pesquisa, enfatizando o seu passo a passo. Assim, não estimulam os sentidos do pesquisador, como se o método científico dispensasse a sensibilidade. O presente "texto" foi escrito para a disciplina Seminários de Pesquisa do PPGCOM-ESPM, com foco no pathos, a fim de aproximar os alunos do conhecimento essencial para se "fazer ciência", aprisionado inteiramente no logos. A cada aula, distribuía-se um "extrato lírico", correspondente a um item constitutivo dos projetos de pesquisa.

Palavras-chave: Metodologia de pesquisa, comunicação, ensino, sensibilidade

\section{ABSTRACT}

Research Methodology is compulsory within the stricto sensu graduate programs in Communication. Although reference works are of good quality, they limit themselves to discuss the process of the elaboration of research projects, with emphasis on its step-by-step. However, you do not stimulate the researcher's expansion of the meanings, as if sensibility were harmful to the scientific method. The present "text" was written for the Research Seminars of the ESPM Graduated Programme in Communication, with a focus on the pathos, in this way it aims at bringing the students near to the essential knowledge necessary to "make science", entirely imprisoned in the logos. At each lecture, a "lyric extract" was distributed, on one of the items of the research projects.

Keywords: Research methodology, communication, teaching, sensibility 


\section{PROJETO}

LANO DE VOO. Onde estamos e para onde vamos. Geografia vista do papel; pelas dobras, insinuam-se os detalhes da paisagem: veja, um rio, uma de suas margens, um cavalo bebendo de suas águas - mas não passe de um trecho, só uma ria do rio. Como um decote: imagina-se o todo, sem desenglobá-lo. Absconsos devem estar seus pormenores, o máximo que se nota é o aqui e o ali de alguns pormaiores. Projeto. Como os cabelos que ocultam a nuca. Por que não erguê-los e beijá-la? Projeto. Como num sonho, vai se desenovelando, em atos lentos ou lépidos. Executa-se à semelhança da música: adágio, andante, alegro. Com sobrenome, que corresponde a estados de espírito: grazioso, com brio, ma non troppo. Quando tarda para se abrir, metáfora de flor, entramos no modo tristíssimo. Quando uma de suas pétalas complexas desabrocha, é imediato que passemos à condição cantábile: Aleluia, aleluia... Para os forjados na cultura do morro, seria outra canção: "Eu canto samba / Porque só assim eu me sinto contente". Projeto. O seu fio, não o de Ariadne. Bem-me-quer e malmequer durante uma raia da vida. Como fabricar, no ventre intelecto, um filho: o mesmo e outro eu no espaço sideral dos signos.

\section{TÍTULO}

Nome. Vocábulo que designa pessoa, bicho ou coisa. Que distingue também ação, estado ou qualidade. Título, honra, reputação. Nome de batismo, de família, de guerra. Nome feio. Próprio. Nome da rosa. A rosa e o rei. A rosa do povo. Drummond. E agora, José? Agora, a náusea. João, Jesus, Judas. A bíblia. O novo e o velho testamento. Assim falava Zaratustra. Em busca do tempo perdido. Aproximação a Almotásim. Dom Quixote. Dona Quitéria. Maria da Piedade, Maria dos Prazeres, Maria das Dores. Tristes trópicos. Itinerário de Pasárgada. Barco a seco. Sagarana. Grande sertão: veredas. Mahabharata. E, em seu interior, Bhagavad-Gita. O deus dos pássaros: Simurg. Ganesha. Vênus. André, meu pai. Helena, minha mãe. E a de Tróia. O jardim das hespérides. O velocino de ouro. Os argonautas. Os astronautas. Os detonautas. Cronópios. Pigmaleão. Édipo. Alceste. Meus dias raros. A cachorra Baleia. Pandora. Zé Bebelo. Macabéa. Capitu. La dolce vita. Luzes da ribalta. Esperando Godot. Cidadão Kane. Malpertuis. A divina comédia. A trágica também. Aulas secretas de um guru. Yogakrisnanda. O nome do primeiro amor. Do último, e até a morte: Juliana. $\mathrm{O}$ nome que não se pode esquecer. $\mathrm{O}$ inominável. $\mathrm{O}$ dicionário Kazar. $\mathrm{O}$ nome de quem vem vindo, de minha semente: Maria Flor. 


\section{RESUMO}

Resumo. A palavra revela seu pleno sentido: só o sumo. Mas o sumo recontado. Então, até o caroço pode entrar, se é que o caroço não é a soma, decantada, de cada gota. O bagaço fica de fora, quando não é o próprio suco, amargo, que se fibrila. Daí que essa síntese, do tudo, não é nada - conquanto, como a vida, é o que lhe basta, ou lhe resta, para dizer a si, e a outros, que outros somos no ato de recordar nossa história - a síntese, do tudo, não é nada, mas é o que cabe. E, se a regra obriga a espremer o grande no grânulo, a botar num copo toda água do oceano (e não apenas encher um copo com água do oceano), então, esse encolhimento, de pura potência, é o que vale. Não deve ser feito de qualquer forma, mas seguindo uma ordem: desidratando um gomo após outro. No caso do oceano, primeiro deve se ajeitar no copo as ondas, espremendo-as uma sobre as outras, depois todos os habitantes marinhos e, por fim, os navios fantasmas e o resto que vige em suas profundezas, inclusive Atlântida. Essa, se não couber em matéria, deve constar em essência. E o que mais? Em resumo, nada. Senão o grânulo cresce e almeja o grande, as águas folgam e se expandem, dois copos para guardar o oceano não constitui desafio tão empolgante. Então, em suma. Resumo do texto: sumo. Resumo do sumo: gota. Resumo da gota: vida. Resumo da vida: quase nada. E esse quase nada? O nosso todo.

\section{PALAVRAS-CHAVE}

As mais simples, de tão complexas: árvore, mesa, casa. E nunca, em hipótese alguma, em estado de dicionário. Sempre acompanhadas, se não de outra palavra, de um gesto, um sinal, um olhar que envelopa o contexto e lhe dá a devida significância. Eu e você, que formam o nós. Não o nós, que nos fratura ao meio, formando um só, inteiro. Não: um nós que são os dois, preservados. Como a lua e o céu, em plenilúnio. Palavras-chave: aquelas que lembram, no seu não dizer, o subentendido, a fechadura, a porta. Sol. Sombra. Mãe. Colo. Yin. Yang. Zaz. Traz. Deus. Demo. Joia. Tralha. Tramela. Cadeado. Palavras-chave. Que abrem, mas também fecham, universos. Nanja. Olimpo. Túnel do tempo. Na escolha e na entrega, considere quem as receberá. Cavalo, Rocinante (para alguns). Cavalo, Marlboro (para outros). Jamais palavras que despalavram: abre-te-segredo, fecha-te-livro. De preferência, palavras cujas próprias letras sofrem de seu sentido: cruz, desespero, dor. Ou se afligem com seu uso: estilete, bússola, granada. Palavras que, abertas, guardam outras em seu útero. Palavras-valise. Palavras-pai. Palavras-filha. Palavras-pássaro. Palavras-voo. Palavras-chave. Aquelas que dizem o que é preciso dizer: tudo. Mas, também, 
que podem não dizer nada: eu te amo. Ou oi, para dar início à conversa. Ou tchau, para cerrá-la.

\section{TEMA}

O tema deve vir de dentro. Dar-lhe corda, tornar suas vísceras transparentes será a tarefa, o modo natural de externá-lo. Não se fascine com temas-vaga-lumes, temas-estrelas, temas-galáxias. Lampejo, modismo, bizarria. $\mathrm{O}$ tema é antes de tudo um simples, e por isso, um forte. Em verdade, está, há muito, amarrado em seu feixe de compreensão - e espanto - ante as coisas. Dispensa laço, anzol, cordame. Peixe que salta das águas e coleia no ar para desafiar as margens, embora nunca deixe de ser o que ele é - rio, lagoa, mar. Tema: apenas um assunto, mas no cio. Fecunde-o. Sem amor, ou mágoa. Com respeito e gratidão. Aceite-o, como o caracol aceita a valva. Pesa-lhe nas costas. Mas é onde seu próprio corpo se recolhe: casa. No cofre do tema, jaz seu objeto. O objeto: a fruta. O tema: a casca. O tema é o início do exame, esfera onde se dará a investigação. Enxame de dúvidas. Nó de luz nas sombras do cadarço. Vasculhe seu íntimo e o tema emergirá, legítimo, inesperado. Você e a doçura do não-ser. Você e os objetos pontiagudos. Os inutensílios, como a poesia. O capital lírico. A pós-saudade. O sono pós-coito. Os pseudopunks no contexto da globalização. Os liliputianos e a biopolítica. Metamorfose: a fixa e a ambulante. E a metamorfose definitiva: morte. Essa, sim, assunto universal. De novo: o tema deve vir de dentro. Punhado de mundo, que se pega com a concha da mão, como trigo de uma saca. Com ele, dia após dia, fazemos o nosso pão. Eis o seu naco.

\section{INTRODUÇÃO}

Ao introduzir, faça as definições cabíveis. Definir: dizer para qual fim algo existe (mesmo que não seja um fim definitivo). Pois, toda definição costuma ser provisória. Ainda assim, pode-se definir tudo, inclusive pelo seu princípio. Princípio: sêmen do querer, ou do sem-querer, que se infiltra no ovo do destino. Ovo do destino: expressão à espera de uma frase viril que a gale. Frase: trecho da língua, como fração, ou, para o tempo, instante. Instante: frase de tempo para a vida. Vida: nunca de uma só vez, com sua história inteira, mas sempre em fatias. Em outras palavras, dias. Palavra: signo. Pássaro furta-cor que muda de sentido conforme o galho em que pousa. Galho: filho. Filho: falha da providência. Falha: força que desvia o certo para outro lado. Certo: aquilo que, represando o errado no ventre, dá-se à luz da realidade. Luz: lápis 
que tira as formas do nada e as realça. Lápis: objeto próprio para definir traços, volumes, figuras - tudo o que, igual ao homem (e sua trajetória) pode ser apagado. Apagado: sem lume; portanto, sem início, só com o seu fim. Fim: algo, mesmo se provisório, já definido na introdução.

\section{OBJETO}

O teórico e o empírico. Separados, ou unidos, como o solo e a água nos terrenos alagadiços. A relação liberdade, sol e cabelos ao vento. A alegria que não quer se secar, depois que saímos do mar. A sola dos pés dos dervixes rodopiantes. As gretas no assoalho de casa. Os gritos das formigas sob os sapatos. A valva do caracol em dia de chuva. A florada das laranjeiras (e seu aroma) na tiara de uma noiva. As margens lodosas de uma lagoa. A malha em contato com o corpo. Expressões do tipo eu rio-me, eu regato-me, eu oceano-me. Os hinos de louvor e os cantos de guerra. Os sonhos encalhados na infância. A pele sobre a pele nos jogos amorosos. O monge deserto de claustros. O primeiro planeta de uma nebulosa. A hera crescendo pelos muros, silenciosamente, em tardes cálidas. As damas-da-noite caídas na calçada. As mulheres grávidas de nuvens; os homens, de tempestade. A poda sazonal de desilusões. As saudades em marcha no dia dos mortos. O drapejar de uma bandeira rasgada. $\mathrm{O}$ movimento imperceptível das estátuas de sal. Os joelhos que não se curvam ante as crenças vãs. $\mathrm{O}$ vão entre o ser e o nada. A maciez de seda de certas rochas. A lama ao redor da árvore e o limo grudado à sua ramagem. A sede que a língua desenha com saliva da nuca até a nádega. O que a casa sente por meio de quem a habita. As palavras de corte e as de carinho no subtexto dos embates. E a humanidade que, em nós mesmos, desconhecíamos.

\section{PROBLEMA}

Até quando a vida dói? O dia em que ela cessa, coincide com o seu fim? Quem disse que não há abismos belos? Por que não dormimos em pé, como os cavalos? Por que fechamos os olhos dos nossos mortos? O fundo do poço tem outro fundo, mais fundo e poço? O céu existe para quem? Para si e mais alguém? Onde fica o repasto das estrelas? Que palavras, sem glória, o crucificado do meio disse aos dois, que o ladeavam? Quem vê a racha irromper nas paredes? Quem vê a flor no ato de abrir-se? Rebelar-se contra o quê? E a pedra, não sente o peso do corpo que nela se deita? Lázaro, pra que te devolver à vida? Apela-se a quem, quando a aflição esfola nossa polpa? Por que seus pés tremulam dentro da água azul? Tremulam ou 
são meus olhos, agitados, que assim os veem? O que dizem à brisa as palmas dos coqueiros? Quem inventou o frescor dos pátios? O que fere mais uma asa, seu fecho ou o voo? Estradas se desenham, como mapas, na sola do pé dos peregrinos? E se uma suspeita nos consumisse, feito vela votiva, até o toco? A existência mais o saber e menos o tempo - como se resolve essa equação? Com quantos "não" se faz uma pergunta? Quantos "sim" se espera de uma resposta?

\section{OBJETIVOS}

Expresso ou não, há em toda ação um objetivo. Por exemplo: deitar o dorso sobre a relva, fechar os olhos e sentir nas mãos a textura das folhas. Deixar o barro moldar os dedos (já que os dedos também são barro) e não o contrário. Permitir à consciência, sempre que possível, a ancoragem das lembranças. Dar ao tempo todo o tempo para que nos pesquise, como se fôssemos (e somos) diferentes das vidas pelas quais ele passa. Entregar-se plenamente, seja a que for - a um pequeno prazer, ou à mais indescritível dor. Ouvir com máxima atenção quando o outro fala, sem pensar em resposta, ouvir com máxima atenção quando o outro fala, para flagrar sob a copa de suas palavras, como a das árvores, o que é sol e o que é sombra. Não se ilhar, nem se montanhar. Combater apenas alguns defeitos, já que outros modelam nossas próprias virtudes. Para os quadros felizes, escolher molduras foscas; para as cenas a esquecer, molduras brilhantes. Usar filtro duplo para as tristezas. Ir, às vezes, embora de si. Tocar a campainha pelo tom do coração - uma só vez, se o mundo estiver em ponto-morto; dez vezes, se sentir a hora (um dia será inevitável) do desespero. Atentar para a diferença entre objetivo geral e específico. Geral: não ver na porta apenas porta. Específico: passar a plaina (e a imaginação) na madeira rugosa até que ela fique lisa. Outro. Geral: estudar o que dizem os veios da pedra. Específico: encostar a orelha na pedra e ouvir, sorrindo, os silêncios circunscritos. Não se abalar, se o objetivo não for inteiramente atingido. Nunca será.

\section{JUSTIFICATIVA}

Porque: para fazer cerca, é preciso moirões, espaços vazios e arame. E, uma vez a cerca estendida, o que era um (lado), em dois se transforma no ato. Quem examina bem o palheiro descobre agulhas - e alfinetes. Em todo veio há uma mina. A pele se esgota pelos poros. Se há queimada, a 
fuligem flutua. Pistas, vestígios e marcas levam a tesouro e também ao fosso. O escuro é que cai, trazendo a noite. Cama tem forma de colo. $\mathrm{O}$ fardo nunca deve superar o comprimento dos braços. Arma tem permissão de tiro, se embainhada junto à farda. Chifre mais inibe que agride. Para os abutres, abutres não enunciam mau agouro. Proezas devem ocultar seu autor. O silêncio é que vertebra a palavra. Ri-se, quando não, para se convencer do próprio regozijo. Há que se dar chão às dúvidas e nuvem às certezas. $\mathrm{O}$ contentamento emigra da agonia. E vice-versa. Pensamentos podem ser de areia e cal. Uma criança, que passa correndo, faz o mundo falar. Um velho, em nirvana, faz o mundo emudecer. $\mathrm{O}$ dolo é culpa do destino. Ternura, um leve susto do aço; por isso dura tão pouco. Felicidade é relâmpago. Poesia é como brasa, sopre e ela se aviva. Justifica-se (tudo) para provar relevância, até de coisas mixas. Por quê? Vai-se grafá-lo aqui da seguinte maneira: separado, com acento no ê, e ponto de interrogação. Resposta: porque (junto), assim é a ciência, com seus vãos acertos.

\section{REFERÊNCIAS}

Obrigatoriamente, o quadro completo, com todas as referências. As que constituem eixos e as pontuais. Nunca a obra de um pop star. A posição do primeiro filósofo a bordejar o tema. Um e outro estudioso que, eras à frente, o suturou a alguma teoria. Os inimigos nunca declarados - nesse caso, para contradizê-los. Os deuses da infância, os demônios contemporâneos. Os fatos que despedaçaram a sua fé na verdade. O final de "A morte do leiteiro": "Por entre objetos confusos, / mal redimidos da noite, / duas cores se procuram, / suavemente se tocam, / amorosamente se enlaçam, / formando um terceiro tom / a que chamamos aurora". O voto de fidelidade que, todo dia, a roseira renova ao vento. As máximas de seu pai (vindas dos antepassados, em estado de poesia ou com a força dos dogmas). Tudo o que diz a sua mãe, mesmo que ela, como costuma ser, desconheça o seu ofício. Tudo, absolutamente tudo o que dizia a sua mãe, se você já a perdeu. $\mathrm{O}$ silêncio de seu gato, quando você retorna depois de trilhar o caminho errado. As ideias mais esdrúxulas, contrárias às suas diretrizes. A certeza do milagre ao ver sobre a terra e sentir, nas mãos nuas, as raízes tortas de uma árvore. Não mencionar somente os puristas, em algum trecho dar voz aos híbridos, aos clowns, aos derrotados (que venceram o esquecimento). E não se esquecer, jamais, de seu amigo de infância. Nem do Manuel, da padaria. 


\section{METODOLOGIA}

Começa-se, seja o que for, agarrando-se ao que as mãos têm de mais próximo - somos todos náufragos, então cada um que pegue o que puder à sua maneira ou no desespero. Para quem prefere, na via oposta, se afogar, o método é irrelevante, e idêntico o resultado, não importa se a opção é nadar pelo alto-mar até não ter mais braços, ou deixar-se levar, sem resistência, pela correnteza, aceitando o nada do não início (também chamado fim). Depois, segue-se do mesmo jeito, em linha reta, a cabeça erguida, ou em ziguezague, de olhos baixos, aos tropeços, ou seguro a cada passo. Experimentar, qualquer coisa que seja: nunca com voracidade; em porções módicas, sentindo nos dedos a consistência, o gosto na língua, o odor nas narinas. Corpus não é amostra. Certifique-se da integridade de seus instrumentos, revise-os antes de usá-los. Barômetro, para medir a pressão atmosférica. Lágrimas, para a largura do amor. Biruta, indica a direção do vento. Saliva, o caminho do prato. Cronômetros marcam o tempo. Fatos (e também palavras) marcam a dor. Faca ou estilete, caco de vidro ou prego, cada um lacera a seu modo. Escolha de acordo com a sua habilidade - e rasgue com esmero, há tanta beleza nos cortes... Águas rasas, às vezes, tocam fundo na memória. Sem procedimentos internos, a árvore não se arvora (para fora). O método é, apenas, uma prescrição para a viagem. Uma bússola primitiva, como o sol. A desvantagem do método? Ser um meio per se, como a existência - e nada prepara melhor para a vida que o viver.

\section{CONCLUSÕES}

Não se conclui nada sem um antes. $\mathrm{E}$ o antes vive em silêncio. $\mathrm{O}$ silêncio se escoa é no escuro. Pelos dutos cinzentos da palavra é que ele sobe, como seiva nobre. Na claridade é que se ouvem as vozes graves. O grito esconde a fome. Quando o desespero passa do ponto, o faminto come a própria boca. O odor metálico do sangue enjoa. A vida se degrada quando a pele se abre. A lepra da ferrugem não dá cabo ao ferro. Mesmo retorcido, o esquecimento segue no tempo, em malhas. Nada sobra, tudo soçobra. Ninguém se acaba com inteireza. Raízes - vias imóveis que se descaminham. O futuro sempre futura. Os pés em rumo falso não deixam rastros, mas ruínas. A taça, de borco, transborda o oco. No pleno o vazio se represa. Desprezo jamais é absoluto. As aranhas, por exemplo, se teiam no desvão dos caibros. A teoria está à mão. A prática, no gesto. $\mathrm{O}$ cume do morro corta as nuvens. O gume do facão, o talo das flores. Vaias são sinceras. Palmas, mentirosas. A peste se veste de sorrisos. Sorrisos prefaciam lágrimas. Donde se conclui que só na 
última linha - como no derradeiro suspiro de um homem - é que se finda uma história.

\section{ANEXOS}

Anexe apenas o essencial, que não cabia aparecer antes, no corpo maior, embora esteja unido a ele como o feto à placenta. A etiqueta de uma roupa vai ao forro, desconfie se estiver do lado de fora. A etiqueta não se entrega, à primeira vista, mas pelo corte, pelo tecido e pela estampa, sabemos de seu naipe. Assim é, também, aquele que bate à sua porta. Mesmo invisíveis, lá estão todas as suas marcas. A cicatriz no rosto, às vezes, é a que menos importa. Lembre-se de que, ao abrir um e-mail, não há como se livrar do que vêm nele atachado. Assim, um homem: quando chega, traz todas as ocorrências de sua história. O filho do primeiro casamento. A queda da moto. O dia que o demitiram por estelionato. Assim, uma mulher: nos olhos, cada um de seus sangramentos. Nos cabelos, as carícias de uns dedos apaixonados e do vento. No jeito de andar, seu pendor para as leis ou para a desobediência. Se sentir que a bolsa pesa sobre os ombros, elimine tudo o que não é perda, ferida, saudade. Com o copo cheio demais, molha-se o queixo. Já o copo vazio não pede sede, clama por espera e paciência. Se seu rosto estiver rígido, desanexe suas crenças, nem se for para dar a elas um respiro. E deixe, deixe o abraço para o final, quando não se espera mais nada de seus braços. Ou o beijo, quando nada mais parecia sair de seus lábios. O beijo é uma palavra. Quase sempre de saída. Costuma causar surpresa quando a palavra, do beijo, é um simples obrigado. Reza o protocolo agradecer logo à entrada. Mas os lábios, em silêncio, mesmo impondo-lhes resistência, vivem trêmulos nas despedidas. $\mathbf{M}$

Artigo recebido em 17 de fevereiro de 2016 e aprovado em 15 de abril de 2016. 